Research Article

\title{
The Uniaxial Creep Characteristics of Red Sandstone under Dry-Wet Cycles
}

\author{
Guangcheng Liu $\mathbb{D}^{1,2}$ Xin Huang $\mathbb{D}^{1},{ }^{1}$ and Jianyong Pang ${ }^{1}$ \\ ${ }^{1}$ School of Civil Engineering and Architecture, Anhui University of Science and Technology, Huainan 232001, China \\ ${ }^{2}$ Huainan Vocational and Technical College, Huainan 232001, China \\ Correspondence should be addressed to Xin Huang; xinh2017@126.com
}

Received 25 April 2020; Revised 22 June 2020; Accepted 11 July 2020; Published 28 July 2020

Academic Editor: Chunshun Zhang

Copyright (c) 2020 Guangcheng Liu et al. This is an open access article distributed under the Creative Commons Attribution License, which permits unrestricted use, distribution, and reproduction in any medium, provided the original work is properly cited.

\begin{abstract}
Water is one of the most important factors that affect the long-term stability of geotechnical engineering structures. Rainfall often results in periodic changes in the water content in underground rock, which is subjected to alternating dry-wet cycles. In this paper, in order to study the short-term and long-term mechanical properties of red sandstone under these dry-wet cycles, a series of uniaxial compressive strength (UCS) tests and multistage creep tests have been carried out on specimens of red sandstone after being treated to different numbers of dry-wet cycles. A scanning electron microscope (SEM) was used to image the different groups of specimens. The test results have shown that the peak strength and the elastic modulus of the red sandstone decreased as the number of dry-wet cycles increased. It is worth noting that the first immersion of the specimens decreased their strength the most, and the negative logarithmic function was able to better reflect the peak strength of the red sandstone and the variation of its elastic modulus in relation to the number of dry-wet cycles. The results of the creep tests have shown that the instantaneous strain and creep strain of the sandstone increased significantly with the increase of the number of dry-wet cycles. A linear function and a negative logarithmic function can be used to describe the instantaneous strain and the creep strain, respectively. The creep duration of the red sandstone in its failure stage decreased with the increase of the number of dry-wet cycles, and the creep rate increased with the increase of the number of dry-wet cycles. Lastly, the failure modes of the red sandstone were observed; the results showed that the angle between the main crack and the axis of creep failure gradually increased with the increase of the number of dry-wet cycles and the angle of the internal friction and the cohesion decreased. In addition, the failure mode of the specimens changed from tensile failure to shear failure. The microstructure of the sandstone showed that the surface of the specimen changed from being compact to being loose, and the mineral particles in the specimen changed from being spherical to being flat and curly; this led to a decrease in the macroscopic mechanical parameters of the sandstone.
\end{abstract}

\section{Introduction}

Water is one of the important factors that affect the stability and safety of underground rock engineering [1-3]. Regardless of whether a project is characterized by shallow geotechnical engineering, such as subway engineering [4], slope foundation pit [5], or deep underground engineering, for example, a coal mine roadway [6, 7], radioactive waste storage [8], or hydropower stations or dams $[9,10]$, the presence of water is often deleterious to these projects and can weaken their durability, stability, and service life. For underground projects that require long-term maintenance, the creep characteristics of the surrounding rock are of great significance in evaluating the long-term stability of geotechnical engineering. In recent years, a large number of scholars have carried out research into the creep characteristics of different types of rock. The results of this research have shown that, for granite [11, 12], limestone [13], sandstone [14], mudstone [15], and many other types of rock, water has a significant impact on their creep behavior. Yang et al. [16] carried out short-term and creep tests of red sandstone under different pore water pressures. For the sandstone's short-term mechanical behavior, an increase in the confining pressure can improve the mechanical 
parameters of the specimen; however, with an increase in the pore water pressure, the peak stress and elastic model of the specimen gradually decreased. The results for the creep mechanical behavior showed that an increase in the pore water pressure will lead to an increase in the deformation of the rock. Grgic and Amitrano [17] studied the effect of the water content on the creep behavior of iron ore through the use of acoustic emission (AE) equipment. They found that an increase in the water content reduced the mechanical parameters of the specimens; the presence of water leads to the development of micro cracks and accelerates the static fatigue of iron ore. Grgic also found that, for iron ore, the strain of the creep can be recovered after the stress disappears, which indicates that the creep mechanism is following a viscoplastic mechanism. Yu et al. [18] and Tang et al. [19] used their own design of water environment tanks to conduct uniaxial compression tests and multistage creep tests on red sandstone specimens in a real-time water environment. The results showed that the creep strain, the creep strain rate, the failure specimens, and the creep threshold stress of saturated specimens were significantly reduced. From the study, it was found that water seeped into new crack tips and accelerated the failure of the rock during the creep process.

In addition, rainfall and a change in the level of the groundwater often result in the surrounding rock of underground engineering to be in a state of dry-wet cycles. The study of the mechanical properties of the rock under dry-wet cycles mostly focuses on its short-term mechanical properties. For example, Yao et al. [20] studied the uniaxial and tensile mechanical properties of sandstone. The results showed that the presence of water can significantly reduce both the compressive strength and the tensile strength of sandstone. As the number of dry-wet cycles increased, the range of the mechanical parameters of the sandstone gradually decreased. In addition, micro images showed that the dry-wet cycles led to an increase in both porosity and cracks in the specimen. Liu et al. [21, 22] subjected both sandstone and argillaceous sandstone to dry-wet cycling and analyzed the deterioration law of the specimens in terms of their mechanical parameters and their macro-damage and micro-damage mechanism. However, there have been few studies on the long-term mechanical properties of different types of rock under dry-wet cycling, for example, Deng et al. [23]. They found that the creep characteristics of red-bed soft rocks in the area of the Three Gorges Reservoir changed significantly after being subjected to dry-wet cycles; their long-term strength decreased, their lateral expansion deformation gradually increased, and the proportion of the stable creep stage gradually decreased. During the waterrock interaction, the shear failure zone of the specimens gradually increased, and the particles became loose and porous. Due to this lack of research, the long-term mechanical properties of different types of rock under dry-wet cycles need to be studied further.

In this paper, red sandstone was taken as the research object; firstly, rock samples were treated with 0 (dry), 1 (wet), and then 3, 6, and 9 dry-wet cycles. Following this, a series of uniaxial compression tests and multistage loading creep tests were carried out on the samples. The variation law of the uniaxial mechanical strength of the red sandstone under the various dry-wet cycles was ascertained. Then, based on the test results, the instantaneous strain, the creep strain, and the creep duration of the specimens of rock during the creep process were studied. Finally, the failure modes of the red sandstone under the different dry-wet cycles were analyzed and summarized; the results can be used to provide a reference to control the safety of underground engineering.

\section{Materials and Methods}

2.1. Sample Preparation. The red sandstone samples were collected from a project in Huainan City, Anhui Province, China. The rock samples were reddish brown with a few nodules and a few white spots. In this experiment, X-ray diffraction (XRD) was performed using a SmartLab High Resolution X-ray Diffraction machine (Figure 1(a)). According to the results of the XRD spectrum (Figure 1(b)), the main components of the red sandstone were quartz, limestone, and iron oxide.

The samples were selected based on the similar P-wave velocity principle and they were machined into cylindrical samples with a diameter of $50 \mathrm{~mm}$ and height of $100 \mathrm{~mm}$, according to the ISRM (International Society for Rock Mechanics) standard [24]. The surface smoothness was controlled within a tolerance of $\pm 0.05 \mathrm{~mm}$, and the vertical deviation between the upper and lower surfaces was controlled within a tolerance of $\pm 0.25^{\circ}$ (Figure 2).

The basic physical parameters of the prepared samples were measured and the results are shown in Table 1.

2.2. Specimen Treatment and Testing Method. The method of grouping the sandstone samples was as follows: the samples were divided into five groups; group I consisted of the dry specimens (0 dry-wet cycles) and group II consisted of the saturated specimens (1 dry-wet cycle). Groups III, IV, and V were treated with 3,6 , and 9 dry-wet cycles, respectively. Three samples from each group were selected for the uniaxial compressive strength (UCS) test and the remaining two samples were used for the creep test under uniaxial step loading.

The dry-wet cycle treatment process was as follows:

(1) The processed specimens were put into the vacuum water retaining instrument and the air in the container was then extracted under a pressure of $0.6 \mathrm{kPa}$. The samples were kept in this state for 3 hours to ensure that the air in the red sandstone had been fully removed. The samples were then submerged in water and kept in that state for 12 hours, so that the water could saturate the red sandstone.

(2) The saturated specimens were then removed from the machine; the surface moisture was wiped off and the samples were then put in the electric drying box. The temperature was set at $105^{\circ} \mathrm{C}$; this was done to ensure that the water in the specimen had fully evaporated, because the boiling point of water is 


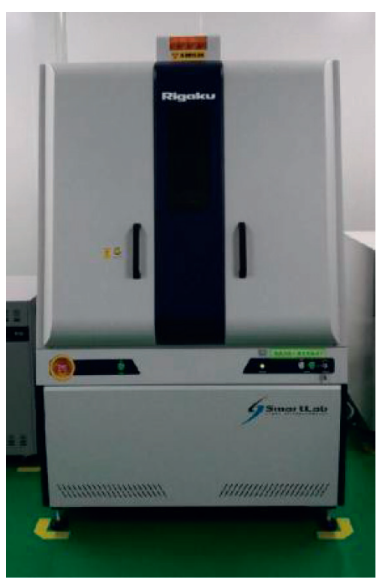

(a)

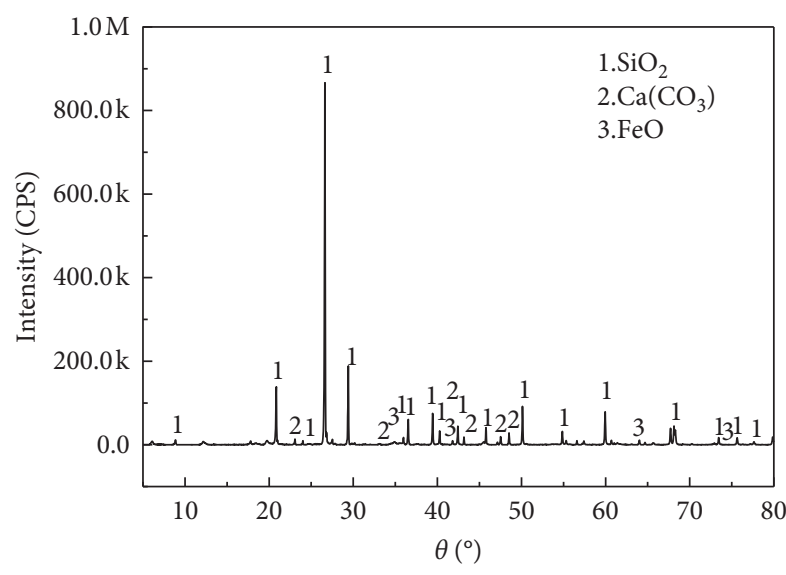

(b)

FIgURe 1: (a) SmartLab $18 \mathrm{~kW}$ machine; (b) XRD diffraction pattern of the red sandstone samples.

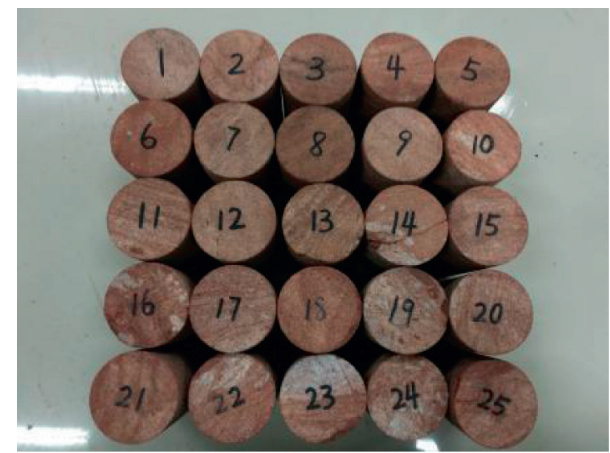

Figure 2: Standardized specimens of the red sandstone.

$100^{\circ} \mathrm{C}$. The samples were kept in the drying box at this temperature for 12 hours.

(3) Steps (1) and (2) were then repeated in order to complete the required dry-wet cycles of the specimens. Throughout this process, the time taken for the dry-wet process of the specimens was the same, and the specimen was returned to a dry state after the dry-wet cycles. The specimens were sealed in a sample bag to prevent them from absorbing moisture from the air and affecting their moisture content.

The diagram of the process of the dry-wet cycles is shown in Figure 3.

2.3. Test Instruments and Loading Scheme. The uniaxial compressive strength tests and creep tests were carried out using an RDL-200 electronic creep relaxation test machine (Figure 4). During the testing process, an extensometer was set in the direction of the height of the specimen to measure its axial deformation.

In order to reduce the influence of the surface smoothness of the specimens on the test and ensure the stability of the test instrument, all of the specimens were preloaded at the beginning of the test with a force of $500 \mathrm{~N}$. Vaseline was applied to the end of the specimens in order to reduce the friction between the test piece and the rigid pressing plate.

The uniaxial compression test adopted the displacement loading mode with a loading rate of $0.02 \mathrm{~mm} / \mathrm{s}$, and the creep test adopted the force loading mode with a loading rate of $1 \mathrm{kN} / \mathrm{min}$. In order to provide sufficient creep deformation time for the specimens, five stages of the step loading were set; each stage of stability lasted for 12 hours. The creep loading path is shown in Figure 5.

\section{Results and Discussion}

\subsection{Uniaxial Mechanical Properties}

3.1.1. Variation of the Uniaxial Mechanical Parameters of the Specimens. From the test results, the uniaxial stress-strain curves of the red sandstone samples that were subjected to different dry-wet cycles were drawn (Figure 6).

From the variations in the curves in the graph, it can be seen that the slope of the curves of the specimens became flatter as the number of dry-wet cycles increased. It could also be seen that, after the peak of each curve, the strain gradually increased, indicating significant ductility. In addition, in order to avoid the influence of both pore compaction and plastic deformation on the slope of the stress-strain curve, the slope of the stressstrain curve within the range of the strain value of $0.2 \times 10^{-2}-0.7 \times 10^{-2}$ was selected as the elastic modulus of the specimen. The elastic modulus of the samples, which was calculated according to formula (1), is shown in Table 2:

$$
E=\frac{\sigma_{2}-\sigma_{1}}{0.7 \times 10^{-2}-0.2 \times 10^{-2}}
$$

where $\sigma_{1}$ denotes the stress when the strain was $0.2 \times 10^{-2}$ $(\mathrm{MPa})$ and $\sigma_{2}$ denotes the stress when the strain was $0.7 \times 10^{-2}(\mathrm{MPa})$.

It can be seen from Table 2 that the stress-strain curve of the samples increased as the number of dry and wet cycles, $n$, increased. The force and the modulus of elasticity of the samples gradually decreased. The peak stress $(\sigma)$ and elastic 
TABLE 1: The average value of the basic physical parameters of the red sandstone.

\begin{tabular}{lcccc}
\hline Physical parameters & Natural mass $(\mathrm{g})$ & Saturated mass $(\mathrm{g})$ & Dry P-wave velocity $(\mathrm{km} / \mathrm{s})$ & Saturation P-wave velocity $(\mathrm{km} / \mathrm{s})$ \\
\hline Value & 471.79 & 483.12 & 4.485 & 5.333
\end{tabular}

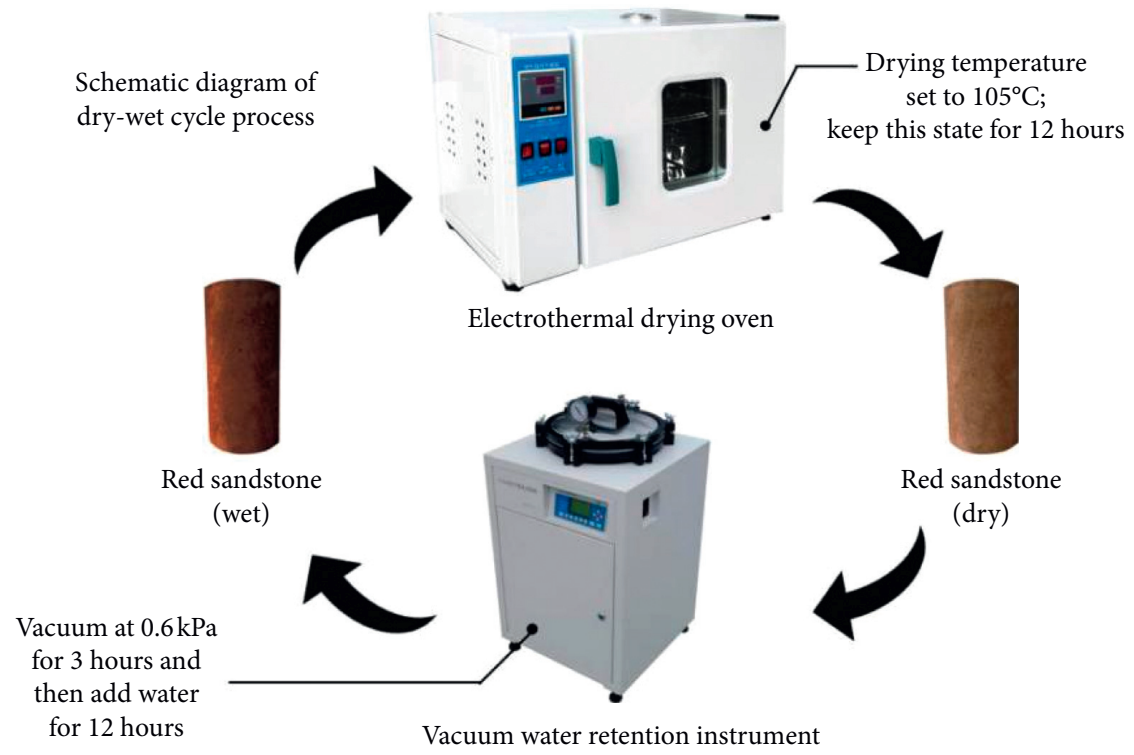

Figure 3: The dry-wet cycle process of the specimens.

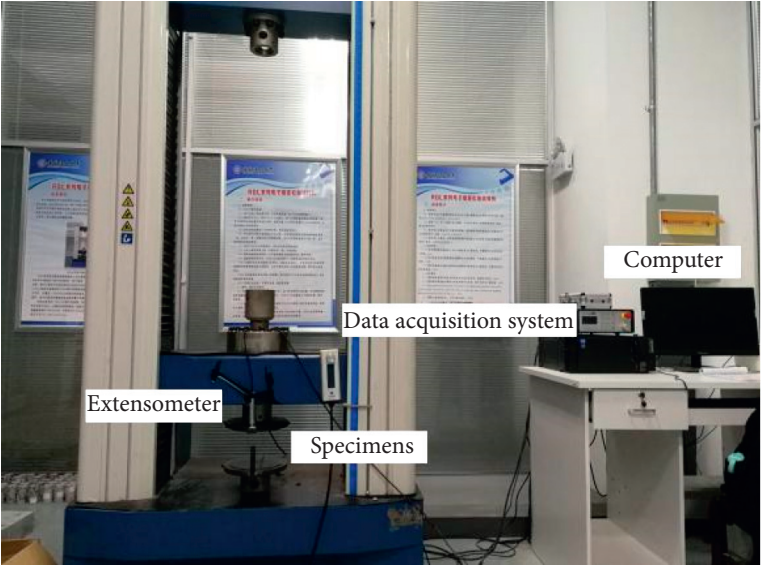

FIgURE 4: The RDL-200 electronic creep relaxation test machine.

modulus $(E)$ of the saturated specimens had been reduced by $35.4 \%$ and $36.3 \%$, respectively, compared with the values of the dry specimens. These results indicate that the water content has a great impact on the properties of the red sandstone, and the dissolution of some of the cement led to a decrease in the mechanical properties of the samples.

According to the data in Table 2, the curves of the mechanical parameters of the samples with regard to the number of dry-wet cycles $(n)$ were drawn, as shown in Figure 7.

The experimental results have shown that the variation trends of both $\sigma$ and $E$ were consistent. It can be seen that the decrease in the mechanical parameters of the samples was

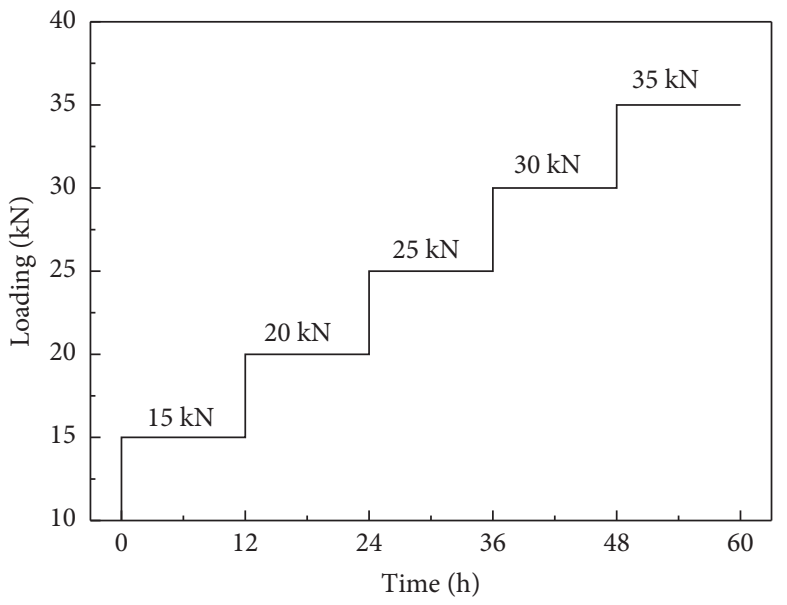

FIGURE 5: Creep loading path of the specimens.

the largest after the first dry-wet cycle, and then the rate of decrease of the samples' mechanical parameters gradually slowed down. It was assumed that the change in the uniaxial mechanical parameters of the red sandstone samples was continuous with the increase of $n$. The function $y=y_{0}\left[1-a \ln \left(x^{b}+1\right)\right][25]$ was used to fit the test results, and the results of the fitting have been shown in formula (2):

$$
\begin{array}{cc}
\sigma=20.67\left[1-0.28 \ln \left(n^{0.83}+1\right)\right], & R^{2}=0.809, \\
E=2.02\left[1-0.27 \ln \left(n^{0.47}+1\right)\right], & R^{2}=0.897,
\end{array}
$$

where $\sigma$ denotes the peak stress, $E$ denotes the elastic modulus, and $n$ is the number of dry-wet cycles. 


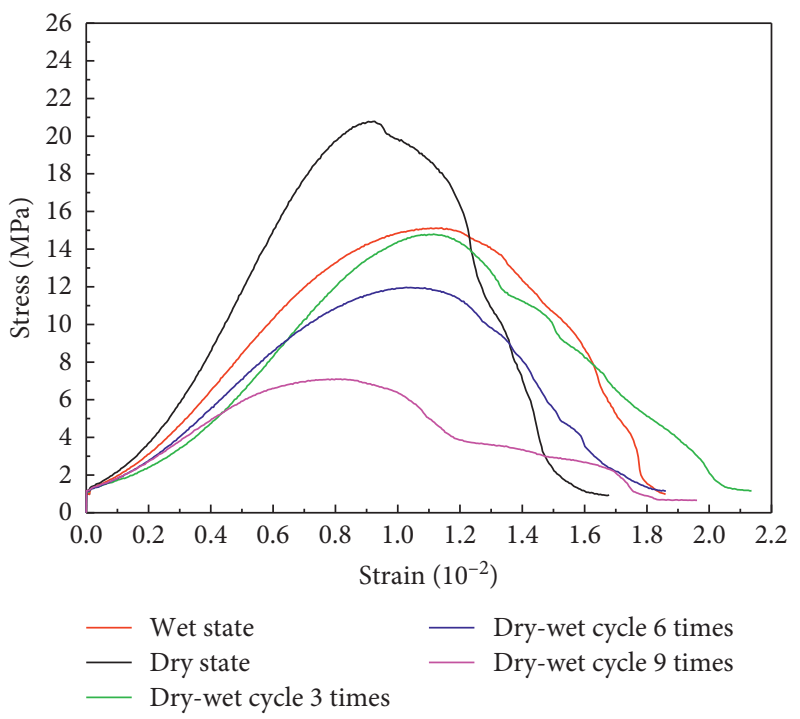

FIGURE 6: Uniaxial stress-strain curve of the red sandstone samples.

TABLE 2: Changes in the uniaxial mechanical parameters of the red sandstone.

\begin{tabular}{lcc}
\hline Number of dry-wet cycles $(n)$ & $\sum(\mathrm{MPa})$ & $E(\mathrm{GPa})$ \\
\hline 0 & 20.746 & 2.717 \\
1 & 15.322 & 1.994 \\
3 & 14.867 & 1.719 \\
6 & 12.197 & 1.466 \\
9 & 7.368 & 1.109 \\
\hline
\end{tabular}

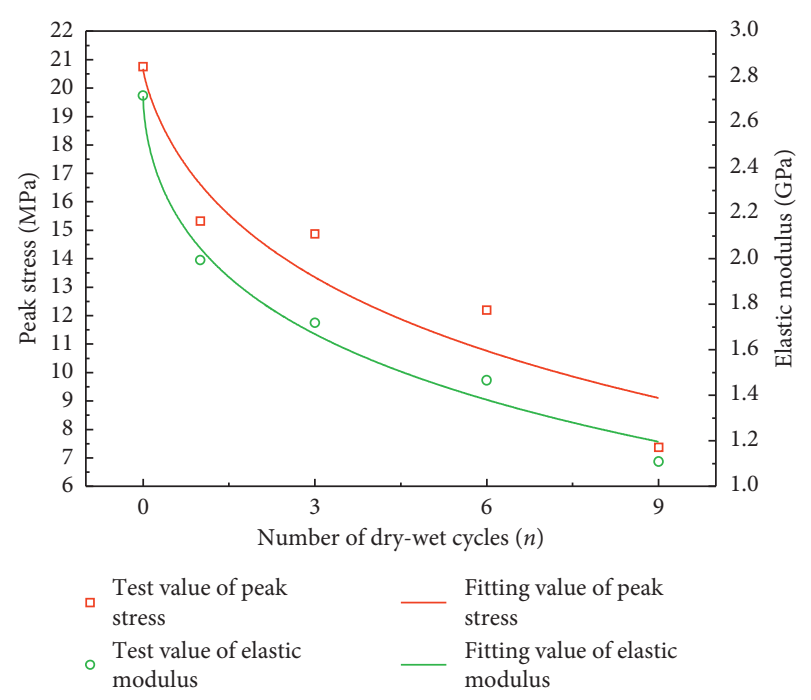

Figure 7: Curve of mechanical parameters of the samples with $n$.

$R^{2}$ of the fitting curve was greater than 0.8 , which indicates that there was a strong correlation between the test curve and the fitting curve; the relative error [26] can be used to further evaluate the test results:

$$
W=\frac{\left|x-x_{p}\right|}{x},
$$

where $W$ is the relative error, $x$ is the test value, and $x_{p}$ is the predicted value. The results of the calculation are shown in Table 3.

The first row in the table denotes the relative error in the peak stress, and the second row in the table denotes the relative error in the elastic modulus. Considering that the rock test has a certain discrete type which led to the error, the overall relative error between the predicted value and the test value was guaranteed to be between 0.004 and 0.256; therefore the prediction was relatively accurate.

The peak strain gradually decreased as the number of dry-wet cycles, $n$, increased. The strain values of the specimens that were subjected to 3,6 , and 9 dry-wet cycles decreased by $4.4 \%, 8.8 \%$, and $29.2 \%$, respectively, compared with the initial saturated state. It should be noted that as the number of dry-wet cycles, $n$, increased, a larger number of postpeak mechanical responses appeared in the specimens; this caused the specimens to show ductility characteristics.

The change in the uniaxial parameters of the specimens has shown that the damage caused by the dry-wet cycles occurred gradually. In the drying stage, the high temperature caused the pore passages of the sandstone particles to expand. In the soaking stage, the excess water washed away a large number of sandstone particles and dissolves the cement; this reduced the degree of intergranular cementation and increased the number of cycles. The more that the pore paths were damaged, the more cracks developed, and the strength of the cracks significantly decreased.

3.1.2. Degradation of the Uniaxial Mechanical Parameters of the Sandstone. According to the variation of both $\sigma$ and $E$ in Table 2, formula (4) for the degree of deterioration proposed by Deng et al. in [27] was used to calculate the relationship between the degree of deterioration of the above three mechanical parameters and the number of dry-wet cycles, $n$ :

$$
S_{i}=\frac{\left(T_{0}-T_{i}\right)}{T_{0}} \times 100 \%,
$$

where $S_{i}$ denotes the total degradation of the sample after $n$ dry-wet cycles, $T_{0}$ represents the values of $\sigma$ and $E$ before immersion in water, and $T_{i}$ represents the values of $\sigma$ and $E$ for the different number of cycles.

The $n-S_{i}$ curve of the total degree of deterioration for each group of parameters after the different number of cycles is shown in Figure 8.

From Figure 8, it can be seen that the number of dry-wet cycles had a great influence on $\sigma$ and $E$; both of them were sensitive to the change in $n$ and demonstrated a linear increasing trend. The total degree of deterioration for $\sigma$ and $E$ reached $64.48 \%$ and $59.18 \%$, respectively, and their degree of deterioration was large.

\subsection{Analysis of the Uniaxial Creep Axial Strain of the Samples.} According to the creep loading path (Figure 5), creep tests of the red sandstone specimens that were subjected to a different number of dry-wet cycles were carried out under uniaxial step loading. According to the test results, the time- 
TABLE 3: The value of $W$ for the different situations.

\begin{tabular}{lccccc}
\hline$n$ & 0 & 1 & 3 & 6 & 9 \\
\hline$W_{\sigma}$ & 0.004 & 0.086 & 0.096 & 0.108 & 0.255 \\
$W_{E}$ & 0.256 & 0.178 & 0.139 & 0.072 & 0.163 \\
\hline
\end{tabular}

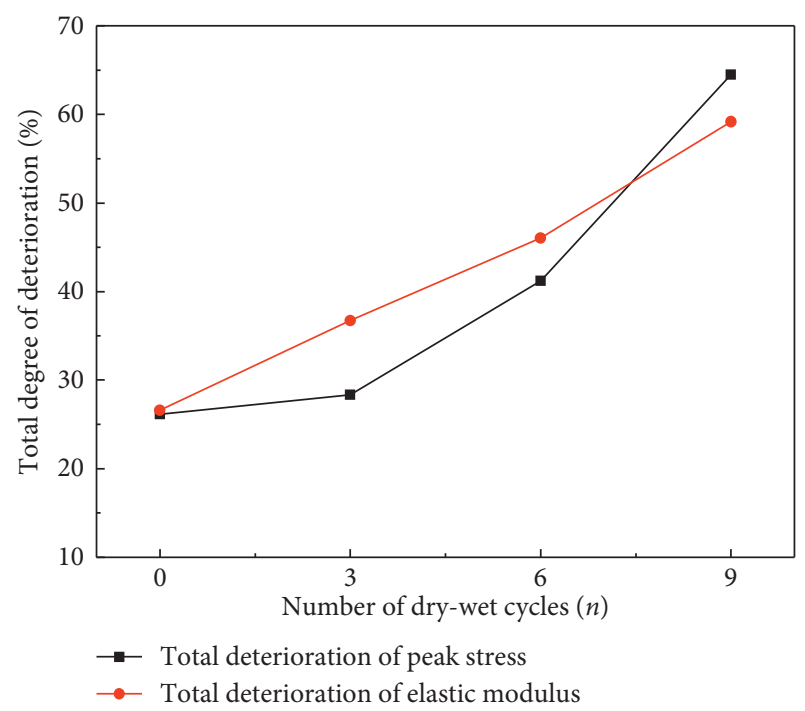

Figure 8: The $n-S_{i}$ curve for each group of parameters.

strain curves of the specimens under the different treatment conditions were drawn, as shown in Figure 9.

\subsubsection{Creep Curve Analysis of the Red Sandstone Specimens} under Uniaxial Step Loading. The creep curves of the red sandstone specimens increased stepwise with the change in the step loading. The instantaneous axial strain occurred at the moment of the stress loading, and then the creep began at the stage of stress stability. After the first stage of stress loading, the axial strain of each group of specimens obviously increased; then the slope of the creep curve gradually decreased and then tended to be stable; after this point, it began to enter the deceleration creep stage and then the stable creep stage. When each group of specimens was loaded at the last stage, the slope of the creep curve gradually increased, and the range of the axial strain also increased. The specimens then entered the accelerated creep stage and eventually broke down. The creep curves of the sandstone specimens fully reflect the three stages of rock creep, and, with the increase of the dry-wet cycles, the stress loading stage required for the creep failure of the red sandstone samples gradually decreased, and the instantaneous axial strain and its increment gradually increased. As a result of this, the creep curves changed from gentle to steep.

\subsubsection{Effect of the Dry-Wet Cycles on the Axial Creep Strain of} the Red Sandstone. The variation of the axial strain of the red sandstone specimens that were subjected to different drywet cycles is shown in Table 4.

According to the data in Table 4, the trend diagram of the axial creep strain of the red sandstone was drawn

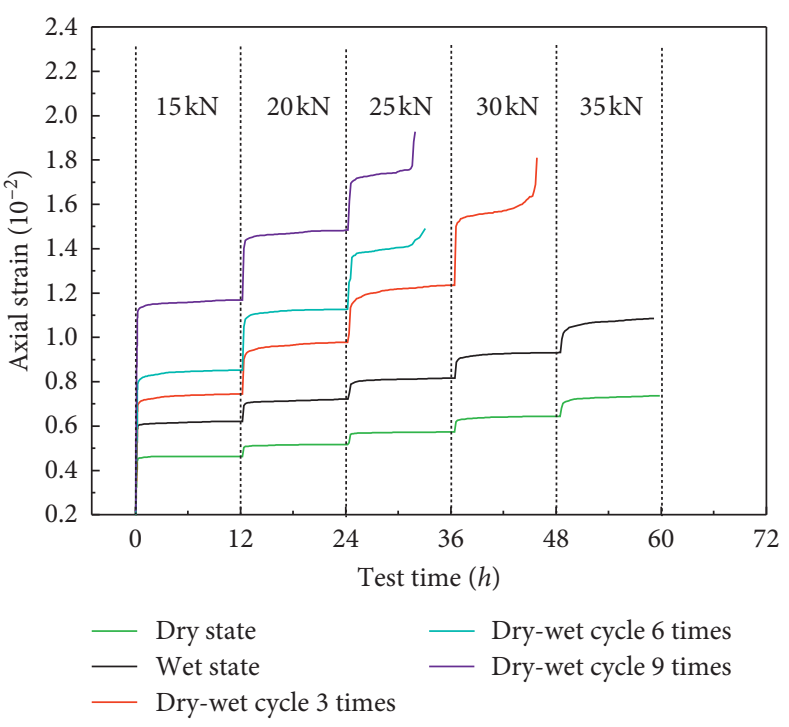

FIgURE 9: Uniaxial compression creep test curves of the red sandstone under different dry-wet cycles.

(Figure 10), in which the creep strain of each stage was calculated according to the following formula:

$$
\Delta \varepsilon=\varepsilon_{b}-\varepsilon_{a},
$$

where $\Delta \varepsilon$ denotes the creep strain at the different stages, $\varepsilon_{a}$ denotes the initial strain values at each stage, and $\varepsilon_{b}$ denotes the end strain values at each stage.

It can be seen from the trend of the variation of the curve in Figure 10 that the creep strain of the red sandstone specimens subjected to a different number of dry-wet cycles was basically the same under the different stress levels. The creep strain of the red sandstone specimens gradually increased with the increase of the loading stage and obviously increased at the failure stage. In addition, with the increase of the dry-wet cycles, the creep of each group of specimens also increased. As the groups of specimens where $n=6$ and 9 were damaged in the third stage of loading, the creep of each group of specimens was analyzed for the first and second stages of loading (Figure 11).

It was assumed that the change of the axial creep with the number of dry-wet cycles, $n$, was continuous; therefore the function $y=y_{0}\left[1-a \ln \left(x^{b}+1\right)\right]$ [25] was used to fit the creep curves. The results of the fitting have been shown in

$$
\begin{array}{ll}
\Delta \varepsilon_{1}=0.014\left[1+1.10 \ln \left(n^{1.35}+1\right)\right], & R^{2}=0.954, \\
\Delta \varepsilon_{1}=0.013\left[1+3.19 \ln \left(n^{0.81}+1\right)\right], & R^{2}=0.810,
\end{array}
$$

where $\Delta \varepsilon_{1}$ are the axial creep values of the specimens under the first stage of loading, $\Delta \varepsilon_{2}$ are the axial creep values of the specimens under the second stage of loading, and $n$ represents the number of dry-wet cycles.

With the increase of $n$ (Figure 11), the creep values of the specimens continuously increased under the same level of stress loading, but the range gradually decreased. Under the first stress loading condition, the creep value increased by $221.4 \%$ from $n=0$ to $n=3$ and by $31.1 \%$ from $n=3$ to $n=9$; the former is 7.12 times higher than the latter. Similarly, 
TABLE 4: Axial strain changes of the red sandstone's creep (unit: $10^{-2}$ ).

\begin{tabular}{|c|c|c|c|c|c|c|c|c|c|c|}
\hline \multirow{2}{*}{ Red sandstone's state } & \multicolumn{2}{|c|}{$s=1$} & \multicolumn{2}{|c|}{$s=2$} & \multicolumn{2}{|c|}{$s=3$} & \multicolumn{2}{|c|}{$s=4$} & \multicolumn{2}{|c|}{$s=5$} \\
\hline & $\varepsilon_{a}$ & $\varepsilon_{b}$ & $\varepsilon_{a}$ & $\varepsilon_{b}$ & $\varepsilon_{a}$ & $\varepsilon_{b}$ & $\varepsilon_{a}$ & $\varepsilon_{b}$ & $\varepsilon_{a}$ & $\varepsilon_{b}$ \\
\hline Dry state & 0.389 & 0.403 & 0.504 & 0.517 & 0.562 & 0.574 & 0.625 & 0.644 & 0.703 & 0.737 \\
\hline Wet state & 0.599 & 0.621 & 0.692 & 0.722 & 0.789 & 0.816 & 0.888 & 0.931 & 0.993 & 1.086 \\
\hline 3 dry-wet cycles & 0.700 & 0.745 & 0.901 & 0.978 & 1.016 & 1.236 & 1.517 & 1.811 & \multicolumn{2}{|c|}{ Destruction } \\
\hline 6 dry-wet cycles & 0.801 & 0.853 & 1.048 & 1.127 & 1.248 & 1.490 & \multicolumn{4}{|c|}{ Destruction } \\
\hline 9 dry-wet cycles & 1.110 & 1.169 & 1.402 & 1.484 & 1.615 & 1.928 & \multicolumn{4}{|c|}{ Destruction } \\
\hline
\end{tabular}

$\varepsilon_{a}$ denotes the initial strain value of each stage; $\varepsilon_{b}$ denotes the end strain value of each stage; $s$ is the loading stage; $s=1,2,3$, 4 .

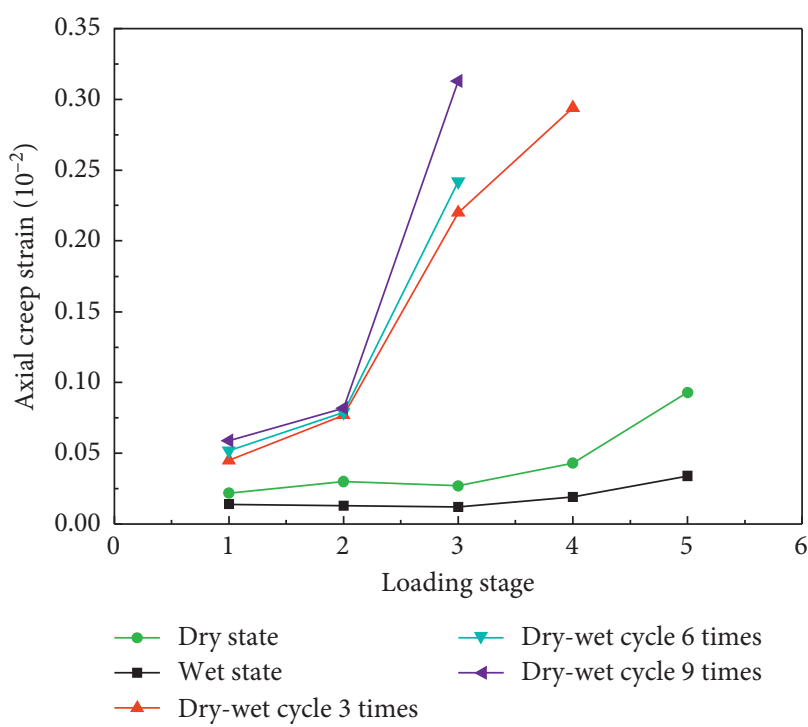

Figure 10: Creep strain changes of the specimens at each loading stage.

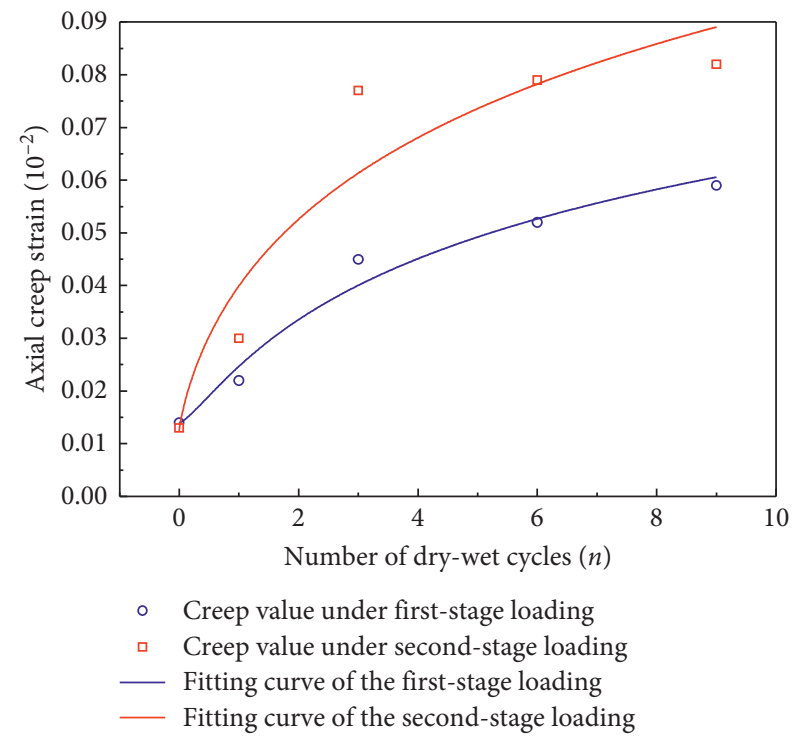

Figure 11: Creep curve of the different loading levels of the specimens.

under the second stage of stress loading, where $n=0 \sim 3$, the increase was $492.3 \%$, and, for $n=3 \sim 9$, the increase was $6.5 \%$; the former is 75.74 times that of the latter. In addition, when $n$ was small, the creep values of the specimens with different loading levels were similar. With the increase of the loading levels, the creep values of the specimens with different loading levels increased with the increase of $n$. This indicates that the dry-wet cycles increased the internal voids, as well as the strain and degree of damage, of the specimens.

3.2.3. Effect of the Dry-Wet Cycles on the Instantaneous Strain of the Red Sandstone. Instantaneous strain refers to the instantaneous strain produced during loading; its value reflects the deformation characteristics of the specimen when it is under instantaneous stress. According to the data in Table 3, the trend diagram of the axial instantaneous strain of the red sandstone was drawn, where the strain of each stage was calculated according to

$$
\Delta \varepsilon_{i}=\varepsilon_{a(s)}-\varepsilon_{b(s-1)},
$$

where $\Delta \varepsilon_{i}$ denotes the instantaneous strain at each stage, $\varepsilon_{a(s)}$ denotes the next stage's initial strain value, and $\varepsilon_{b(s-1)}$ denotes the strain values at the end of the current phase; $s=1$, $2,3,4,5$.

With the progression of the loading stage (Figure 12), the curves of each group displayed a sudden drop at first, and then a significant inflection point appeared at the second stage; after this, the rate of decline slowed down and then slowly rose after reaching its lowest point. The instantaneous strain of each group of specimens increased after reaching a minimum at the third stage until failure occurred. At the same time, the number of dry-wet cycles had a significant effect on the initial instantaneous strain of the specimens, and its value increased with the increase of $n$. In addition, because the groups of specimens where $n=6$ and 9 were damaged in the third stage of loading, the first and second stages of loading were selected to be used to analyze the variation of the instantaneous variables with $n$ for each group of specimens (Figure 13).

It was assumed that the change of the axial instantaneous strain with the number of dry-wet cycles $n$ was continuous; therefore the function $y=a x+b$ was used to fit the strain curves. The results of the fitting have been shown in

$$
\begin{array}{ll}
\Delta \varepsilon_{i 1}=0.06969 n+0.45499, & R^{2}=0.919, \\
\Delta \varepsilon_{i 1}=0.01703 n+0.08649, & R^{2}=0.872,
\end{array}
$$

where $\Delta \varepsilon_{i 1}$ is the axial instantaneous strain value of the specimen under the first-order stress loading condition, $\Delta \varepsilon_{i 2}$ is the axial instantaneous strain value of the specimen under 


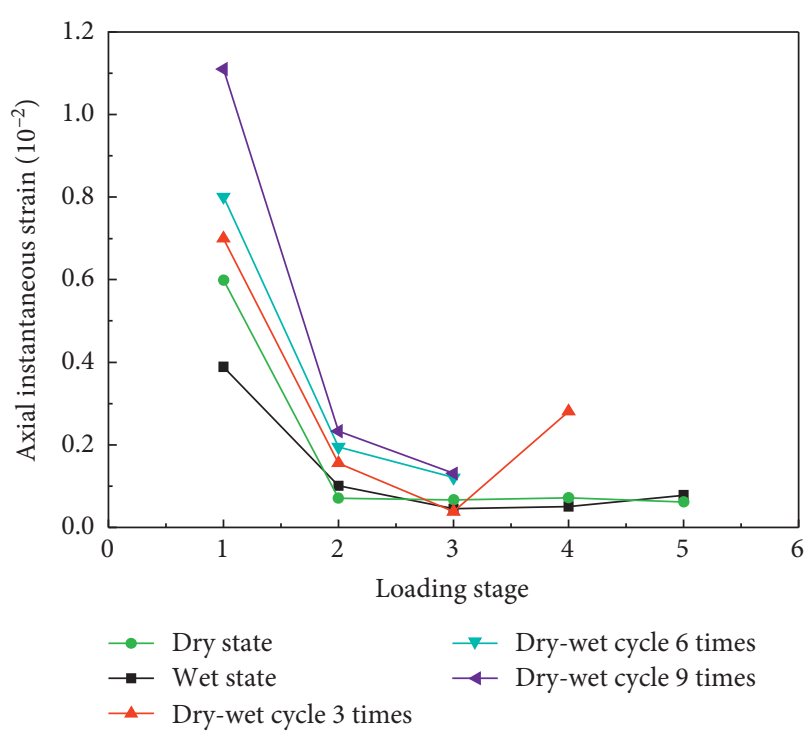

FIGURE 12: Instantaneous change of the strain in the specimens at each loading stage.

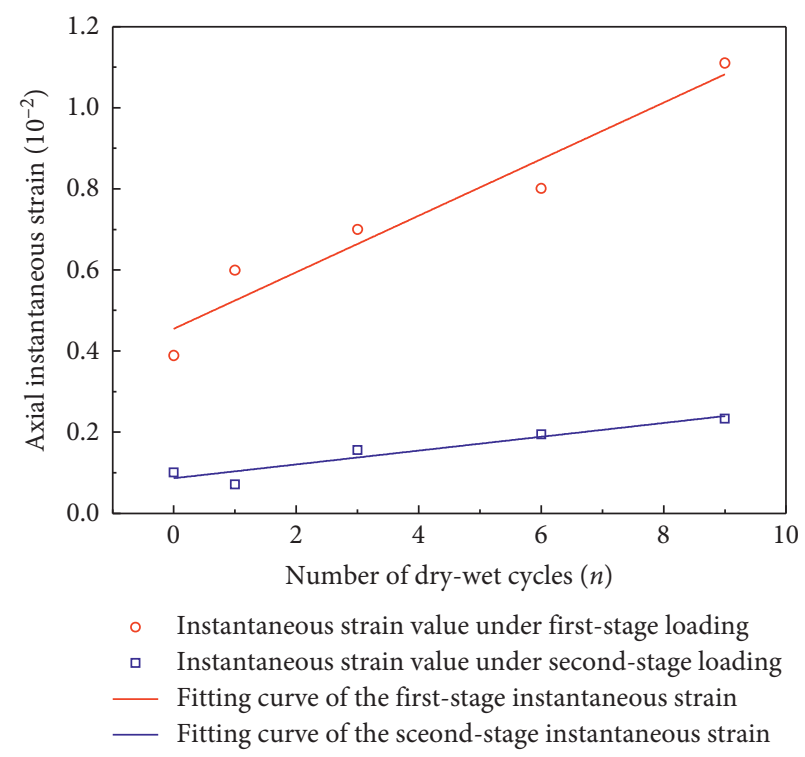

Figure 13: The instantaneous strain curves at the different loading levels of the specimens.

the second-stage stress loading condition, and $n$ is the number of dry-wet cycles.

From the curves, it can be seen that as $n$ increased, the instantaneous strain increased linearly under the same stress level, and the rate of the instantaneous strain growth under the first stress level was 4.10 times higher than that under the second stress level. This was due to the compaction of the voids and primary cracks in the specimens at the initial stage of loading, which resulted in large deformation of the samples. In addition, the instantaneous strain under the first stress loading was much larger than that under the second stress loading, and the larger the value of $n$ was, the greater the difference between the two values was. The difference between the two values was only $0.288 \times 10^{-2}$ for $n=0$, and the difference between the two was $0.877 \times 10^{-2}$ when $n=9$; this was an increase of $204.5 \%$. This indicates that the number of dry-wet cycles had a significant effect on the instantaneous deformation of the specimens. The larger the number of dry-wet cycles, the greater the increase of the strain value of the samples. This indicates that the pores and cracks in the specimens developed gradually and the degree of damage increased further.

3.3. Effect of Dry-Wet Cycles on the Failure Stress Stage. In the failure stress stage of the specimens of the red sandstone, the phenomena of a sudden increase in the strain and a rapid increase in the strain rate often occurred; this is called the accelerated creep stage. The analysis of the load, the creep duration, the strain, and the strain rate of rock in this stage are of immense significance in judging the failure situation of the rock. The creep behavior of each group of specimens under the last stress loading stage is shown in Table 5.

According to the data in Table 4, as the number of drywet cycles increased, the failure load of the specimens gradually decreased, and the dry and saturated specimens still showed no obvious signs of failure under a load of $35 \mathrm{kN}$. When $n=3$, accelerated creep failure occurred at a load of $30 \mathrm{kN}$, and when $n=6$ and 9 , failure occurred at a load of $25 \mathrm{kN}$. At the same load level, as $n$ increased, the duration of the failure stage gradually decreased and the instantaneous strain rate and the average creep rate gradually increased. The ranges of increase for $n=6$ and 9 were $8.26 \%$ and $49.68 \%$, respectively.

3.4. Effect of the Dry-Wet Cycles on the Creep Failure Morphology of the Red Sandstone. The creep failure modes of the red sandstone specimens after the different number of drywet cycles showed certain characteristics. As the dry red sandstone specimens did not suffer obvious damage during the creep stage, the specimens were subjected to an additional loading stage (load $40 \mathrm{kN}$ ) during the test process, which caused the specimens to fail (see Figure 14).

The failure modes of the dry red sandstone specimens were two parallel cracks that ran through the body of the samples, which showed obvious tensile failure characteristics. The failure modes of the saturated specimens were similar to those of the dry specimens. There were two parallel cracks running parallel to the longitudinal axis, but they did not penetrate all the way through the samples. With the increase of the number of dry-wet cycles, surface shells peeled off the surface of the specimen, and the angle between the main crack and the longitudinal axis increased, thus showing the characteristics of shear failure.

The fracture surfaces of the samples were analyzed according to the Mohr-Coulomb criterion. The angle between the fracture surfaces was $\alpha$, as shown in Figure 15.

It can be seen from Figure 15 that the specimen was not damaged for $n=0$ and $n=1$. Therefore, when $n=3$, $\alpha=13^{\circ}$, when $n=6, \alpha=18^{\circ}$, and when $n=9, \alpha=26^{\circ}$. The 
TABLE 5: Statistics of the creep parameters of the red sandstone under the failure load level.

\begin{tabular}{lcccc}
\hline $\begin{array}{l}\text { Red sandstone's } \\
\text { state }\end{array}$ & Failure load $(\mathrm{kN})$ & $\begin{array}{c}\text { Duration of the } \\
\text { damage phase }(\mathrm{h})\end{array}$ & $\begin{array}{c}\text { Instantaneous } \\
\text { strain rate }\left(\mathrm{h}^{-1}\right)\end{array}$ & $\begin{array}{c}\text { Average creep } \\
\text { strain rate }\left(10^{-2} * \mathrm{~h}^{-1}\right)\end{array}$ \\
\hline Dry state & 35 & 11.8 & 0.936 & 0.308 \\
Wet state & 35 & 11.2 & 0.744 & 0.882 \\
3 dry-wet cycles & 30 & 9.8 & 3.372 & 3.249 \\
6 dry-wet cycles & 25 & 9.1 & 1.452 & 2.788 \\
9 dry-wet cycles & 25 & 7.9 & 1.572 & 4.173 \\
\hline
\end{tabular}

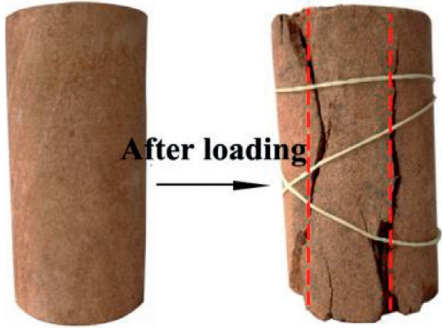

(a)

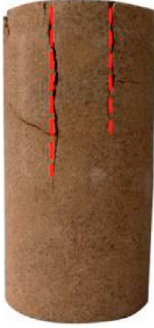

(b)

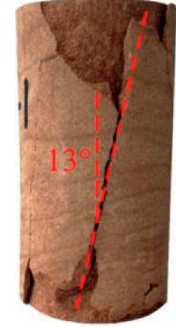

(c)

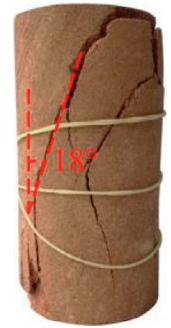

(d)

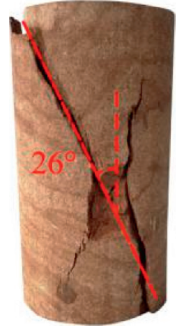

(e)

FIGURE 14: Failure modes of the red sandstone samples under various dry-wet cycles: (a) $n=0$, (b) $n=1$, (c) $n=3$, (d) $n=6$, and (e) $n=9$.

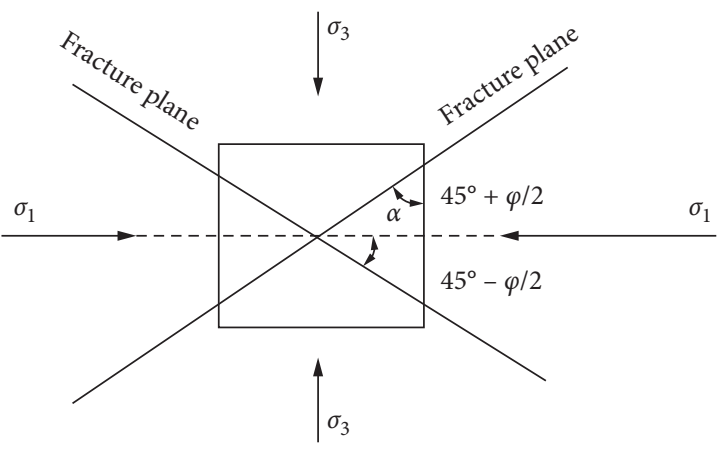

Figure 15: Diagram of fracture angle of the red sandstone samples.

internal friction angle $\varphi$ of the specimen was calculated according to formula (9), and the cohesion $c$ of the specimen was calculated according to formula (10); the results of the calculation are shown in Table 5:

$$
\begin{gathered}
\alpha=45^{\circ}-\frac{\phi}{2}, \\
\sigma_{1}=\frac{1+\sin \phi}{1-\sin \phi} \sigma_{3}+\frac{2 c \cos \phi}{1-\sin \phi},
\end{gathered}
$$

where $\alpha$ denotes the angle between the main stress direction and the fracture surface, $\varphi$ is the internal friction angle of the specimen, $c$ is the cohesion value of the specimen, $\sigma_{1}$ is the maximum main stress, and $\sigma_{3}$ is the minimum main stress, where $\sigma_{3}=0$.

It can be seen from Table 6 that the internal friction angle and cohesion of the specimens were significantly reduced as the dry-wet cycles increased, which shows that the particles in the specimen became dislocated and were lost during the dry-wet cycles, leading to a decline in the macro mechanical properties of the specimens. During the drying process of the rock, the particles expanded,
TABLE 6: Variation of $\varphi$ and $c$ with the number of dry-wet cycles of the red sandstone.

\begin{tabular}{lccc}
\hline$n$ & 3 & 6 & 9 \\
\hline$\sigma_{1}(\mathrm{MPa})$ & 15.3 & 12.7 & 12.7 \\
$\varphi\left({ }^{\circ}\right)$ & 64 & 54 & 38 \\
$c(\mathrm{MPa})$ & 8.66 & 6.16 & 4.10 \\
\hline
\end{tabular}

resulting in compressive stress at the contact points between the particles. During the water saturation treatment, the rock particles encountered the contraction of the water during cooling which transformed the compressive stress to tensile stress. In this process of repeated expansion and contraction, cracks were produced at the contact points between the rock's particles; as a result, water could penetrate deeper areas of the rock's interior [28]. After repeatedly alternating within "dry-saturated", a type of free reciprocating movement of the water from the inside to the outside and then from the outside to the inside occurred in the rock [29]. Under the long-term action of this stress, the deformation of the rock became larger and larger, and the degree of deterioration also increased.

3.5. Effect of the Dry-Wet Cycles on the Microstructure of the Red Sandstone. Through the use of the Hitachi S-3400N scanning electron microscope (SEM), the micro images were produced. An SEM is an electronic optical device (as shown in Figure 16), which can be used to observe and image the micromorphology of a sample, as well as its structure and composition.

As the SEM samples needed to be dried, it was impossible to image the micro structure of the specimens in a saturated state; therefore images of 500 times and 1000 times magnification of the samples subjected to $0,3,6$, and 9 drywet cycles were taken, as shown in Figure 17. 


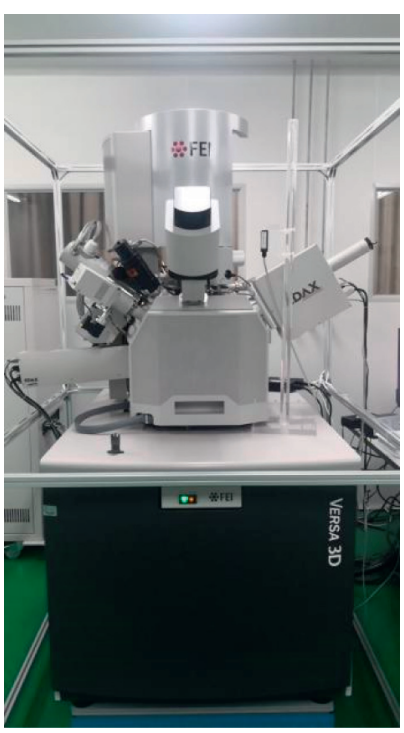

Figure 16: The Hitachi S-3400N scanning electron microscope.

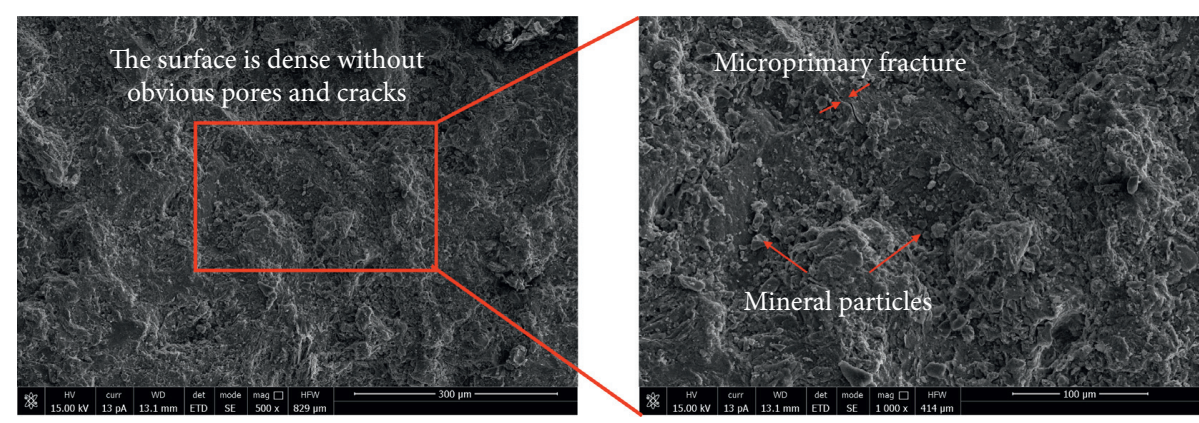

(a)

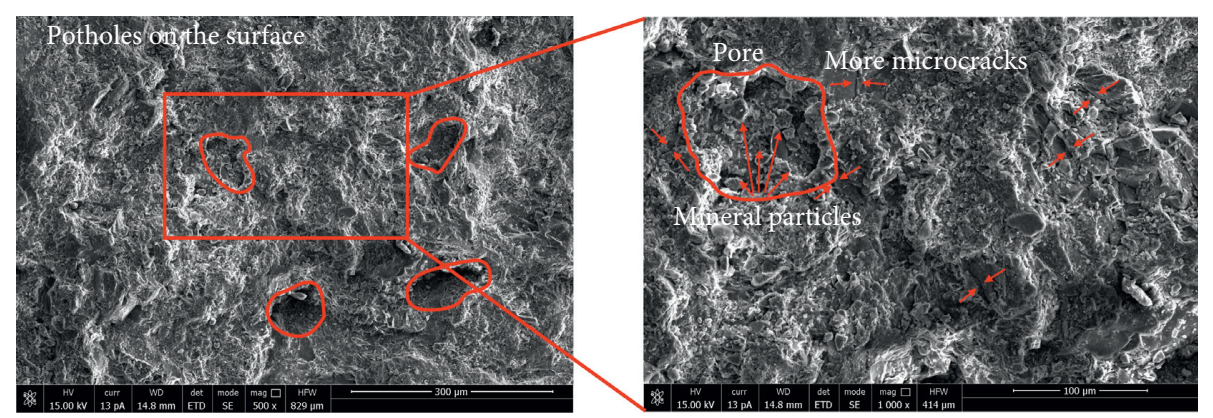

(b)

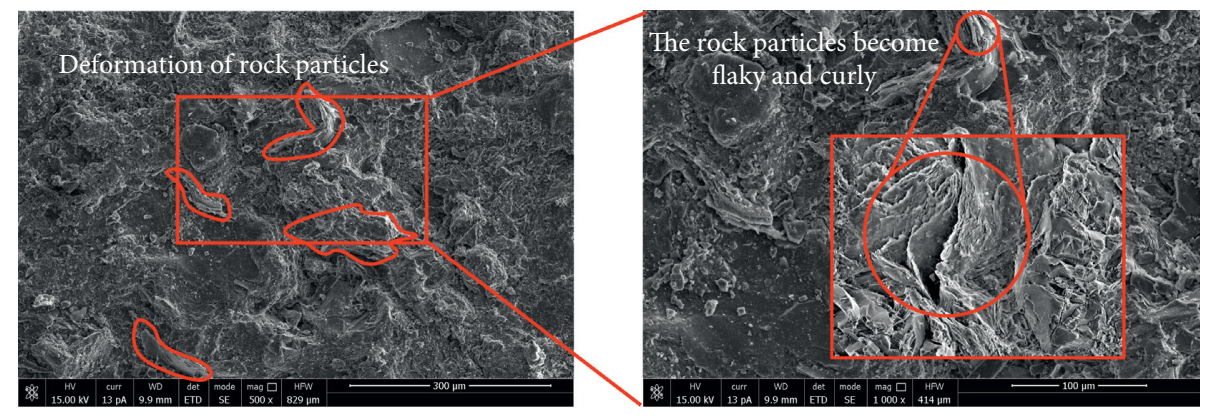

(c)

Figure 17: Continued. 


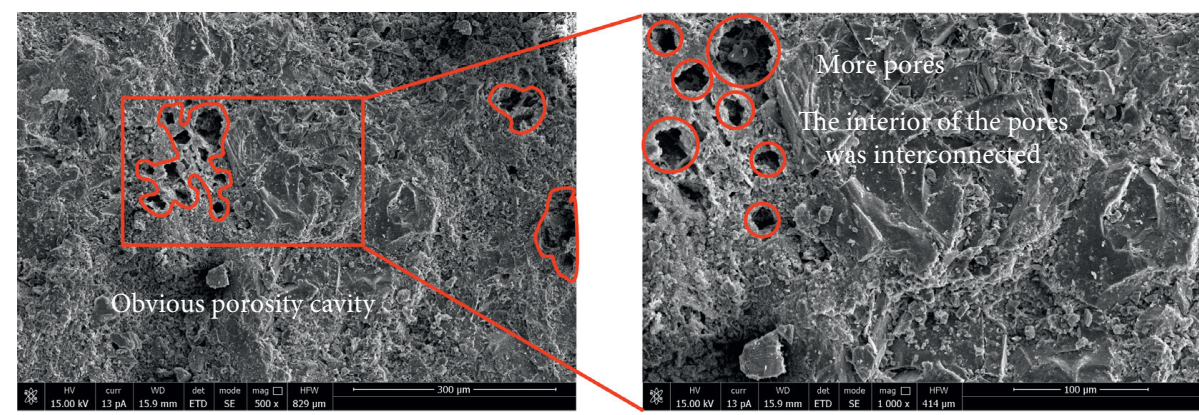

(d)

FIGURE 17: Evolution of the micro structure of the red sandstone with $n$ : (a) $n=0$, (b) $n=3$, (c) $n=6$, and (d) $n=9$.

From the micro images, it can be seen that the surface structure of the red sandstone under the action of the drywet cycles displayed four stages: a flat and compact stage, a pore development stage, a particle deformation stage, and a pore connection stage.

As shown in Figure 17(a), the surface of the specimen was dense, showing only a small number of micro primary fractures and mineral particles; the integrity of the specimen was high. After 3 dry-wet cycles (Figure 17(b)), the surface of the specimen began to show potholes. It can be seen from the image that it was enlarged 1000 times, that there were also a large number of mineral particles in the potholes, and that the surface cracks had gradually increased, indicating that pores had begun to develop. After 6 dry-wet cycles (Figure 17(c)), except for the continuous development of pores, it was found that the particles on the surface of the specimen were deformed and were flaky and curly. This was because the repeated dry-wet cycles produced the mineral particles under the alternating action of tensile and compressive stress, resulting in double compression making them flaky and curly under the action of the tensile force, thus further decreasing the mechanical properties. After 9 dry-wet cycles (Figure 17(d)), the pores on the surface of the specimen had enlarged and had connected with each other, and the structure became loose, similar to that of Swiss cheese. On a macro level, the peak stress was reduced, but the postpeak mechanical response increased, and the specimen began to display ductile failure.

\section{Conclusions}

In this paper, samples of red sandstone were subjected to dry-wet cycles, and uniaxial compression tests and creep tests were carried out. The variation of the uniaxial mechanical parameters (peak stress and elastic modulus) and the uniaxial creep parameters (creep curve, axial creep strain, and instantaneous creep rate) with regard to the number of dry-wet cycles was analyzed. The creep parameters and the failure morphology of the specimens in the failure stage were investigated. The evolution of the microstructure of the red sandstone samples under different dry-wet cycles was observed and analyzed through the use of SEM; from this, the following conclusions were obtained:
(1) As the number of dry-wet cycles increased, the mechanical parameters continuously decreased; the reduction law of the samples was the same. A uniform function was used to fit the test values, and good fitting was achieved. In particular, the first immersion had the biggest influence on the peak stress and elastic modulus of the samples: the reduction ranges were $35.4 \%$ and $36.3 \%$, respectively. The results of the degradation analysis showed that the peak stress and elastic modulus were sensitive to the response of $n$, and the degree of degradation of the samples was $64.48 \%$ and $59.18 \%$, respectively.

(2) As the loading grade increased with the increase of the number of dry-wet cycles, the creep curves of the samples showed a step-by-step increase and the instantaneous creep increased and the creep stage decreased. Under the same number of dry-wet cycles, the creep decreased gradually with the increase of the loading grade. At the same loading level, the creep increased with the increase of the dry-wet cycles, but the increase gradually lessened. The creep curves approximately matched the logarithmic function curve. The instantaneous strain of the samples increased linearly with the number of drywet cycles.

(3) With the increase of the number of dry-wet cycles, the duration of the accelerated creep stage decreased in the samples and the instantaneous strain rate and the average creep rate gradually increased. The failure mode of the samples after creep has shown that, with the increase of the number of dry-wet cycles, the internal friction angle and the cohesion obviously decreased, and the failure mode changed from tensile failure to shear failure.

(4) With the increase of the number of dry-wet cycles, the microstructure of the red sandstone experienced four stages in turn: a flat and compact stage, a pore development stage, a particle deformation stage, and a pore connection stage. The surface morphology of the specimens changed from compact to porous as the cycles increased, and the mineral particle 
morphology changed from spherical to flaky. This is the main reason for the short-term and long-term strength reduction of red sandstone.

\section{Data Availability}

The datasets generated and analyzed during the current study are available from the corresponding author upon reasonable request.

\section{Conflicts of Interest}

The authors declare that there are no conflicts of interest regarding the publication of this paper.

\section{Acknowledgments}

This work was supported by the key project of Natural Science Foundation of Anhui Province, Department of Education (KJ2019A1043).

\section{References}

[1] Y.-F. Chen, J.-M. Hong, H.-K. Zheng, Y. Li, R. Hu, and C.-B. Zhou, "Evaluation of groundwater leakage into a drainage tunnel in Jinping-I Arch Dam foundation in southwestern China: a case study," Rock Mechanics and Rock Engineering, vol. 49, no. 3, pp. 961-979, 2016.

[2] J. Hansmann, S. Loew, and K. F. Evans, "Reversible rock-slope deformations caused by cyclic water-table fluctuations in mountain slopes of the Central Alps, Switzerland," Hydrogeology Journal, vol. 20, no. 1, pp. 73-91, 2012.

[3] S. J. Miao, H. Wang, M. F. Cai et al., "Damage constitutive model and variables of cracked rock in a hydro-chemical environment," Arabian Journal of Geosciences, vol. 11, no. 2, p. 19, 2018.

[4] Z. Zhou, H. Yang, X.-c. Wang, and Q.-f. Zhang, "Fractured rock mass hydraulic fracturing under hydrodynamic and hydrostatic pressure joint action," Journal of Central South University, vol. 23, no. 10, pp. 2695-2704, 2016.

[5] Y. C. Zhang, H. F. Deng, W. Wang et al., "The dynamic response law of bank slope under water-rock interaction," Advances in Civil Engineering, vol. 2018, Article ID 1306575, 10 pages, 2018.

[6] T. Chen, Q.-1. Yao, F. Wei et al., "Effects of water intrusion and loading rate on mechanical properties of and crack propagation in coal-rock combinations," Journal of Central South University, vol. 24, no. 2, pp. 423-431, 2017.

[7] Z. Sha, H. Pu, M. Li et al., "Experimental study on the creep characteristics of coal measures sandstone under seepage action," Processes, vol. 6, no. 8, p. 110, 2018.

[8] S. P. Jia, L. W. Zhang, B. S. Wu, H. D. Yu, and J. X. Shu, “A coupled hydro-mechanical creep damage model for clayey rock and its application to nuclear waste repository," Tunnelling and Underground Space Technology, vol. 74, pp. 230246, 2018.

[9] W.-y. Xu, R.-b. Wang, W. Wang, Z.-l. Zhang, J.-c. Zhang, and W.-y. Wang, "Creep properties and permeability evolution in triaxial rheological tests of hard rock in dam foundation," Journal of Central South University, vol. 19, no. 1, pp. 252-261, 2012.
[10] A. El Naqa and M. Al Kuisi, "Hydrogeochemical modeling of the water seepages through Tannur Dam, southern Jordan," Environmental Geology, vol. 45, no. 8, pp. 1087-1100, 2004.

[11] J. S. Hong and S. Jeon, "Characteristics of creep deformation behavior of granite under uniaxial compression," Tunnelling and Underground Space, vol. 14, no. 1, pp. 69-77, 2004.

[12] X. Wang, B. Hu, H. Tang, X. Hu, J. Wang, and L. Huang, "A constitutive model of granite shear creep under moisture," Journal of Earth Science, vol. 27, no. 4, pp. 677-685, 2016.

[13] Y. Liu, C. Liu, Y. Kang, D. Wang, and D. Ye, "Experimental research on creep properties of limestone under fluid-solid coupling," Environmental Earth Sciences, vol. 73, no. 11, pp. 7011-7018, 2015.

[14] Z. S. Luo, J. L. Li, Q. Jiang et al., "Effect of the water-rock interaction on the creep mechanical properties of the sandstone rock," Periodica Polytechnica-Civil Engineering, vol. 62, no. 2, pp. 451-461, 2018.

[15] X.-l. Huang, J.-j. Liu, C.-h. Yang, and J.-w. Chen, "Experimental investigation of Daqing Oilfield mudstone's creep characteristic under different water contents," Journal of Central South University of Technology, vol. 15, no. S1, pp. 471-474, 2008.

[16] S.-Q. Yang, H.-W. Jing, and L. Cheng, "Influences of pore pressure on short-term and creep mechanical behavior of red sandstone," Engineering Geology, vol. 179, pp. 10-23, 2014.

[17] D. Grgic and D. Amitrano, "Creep of a porous rock and associated acoustic emission under different hydrous conditions," Journal of Geophysical Research: Solid Earth, vol. 114, Article ID B10201, 2009.

[18] C. Yu, S. Tang, C. A. Tang et al., "The effect of water on the creep behavior of red sandstone," Engineering Geology, vol. 253, pp. 64-74, 2019.

[19] S. B. Tang, C. Y. Yu, M. J. Heap, P. Z. Chen, and Y. G. Ren, "The influence of water saturation on the short- and longterm mechanical behavior of red sandstone," Rock Mechanics and Rock Engineering, vol. 51, no. 9, pp. 2669-2687, 2018.

[20] H. Y. Yao, Y. Zhu, and P. Wu, "Research on uniaxial compression and tension tests of sandstone subjected to dryingwetting cycle," Disaster Advances, vol. 6, no. S3, pp. 388-392, 2013.

[21] X. R. Liu, Z. J. Wang, Y. Fu et al., "Macro/Microtesting and damage and degradation of sandstones under dry-wet cycles," Advances in Materials Science and Engineering, vol. 2016, Article ID 7013032, 16 pages, 2016.

[22] X. Liu, M. Jin, D. Li, and L. Zhang, "Strength deterioration of a shaly sandstone under dry-wet cycles: a case study from the Three Gorges Reservoir in China," Bulletin of Engineering Geology and the Environment, vol. 77, no. 4, pp. 1607-1621, 2018.

[23] H. F. Deng, M. L. Zhou, J. L. Li et al., "Creep degradation mechanism by water-rock interaction in the red-layer soft rock," Arabian Journal of Geosciences, vol. 9, no. 12, p. 601, 2016.

[24] R. Ulusay and J. Hudson, The Complete ISRM Suggested Methods for Rock Characterization, Testing and Monitoring 1974-2006, International Society for Rock Mechanics, Salzburg, Austria, 2007.

[25] X. R. Liu, L. Zhang, and Y. Fu, "Experimental study of mechanical properties of argillaceous sandstone under wet and dry cycle in acid environment," Rock and Soil Mechanics, vol. 35, no. 2, pp. 45-52, 2014, in Chinese.

[26] X. Huang, J. Y. Pang, G. C. Liu et al., "Experimental study on physicomechanical properties of deep sandstone by coupling 
of dry-wet cycles and acidic environment," Advances in Civil Engineering, vol. 2020, Article ID 2760952, 17 pages, 2020.

[27] H. F. Deng, Z. Y. Xiao, J. Li, and Y. Hu, "Deteriorating change rule test research of damage sandstone strength under waterrock interaction," Chinese Journal of Rock Mechanics and Engineering, vol. 34, no. 1, pp. 2690-2698, 2015, in Chinese.

[28] P. Yuan and Q. Y. Ma, "Split Hopkinson pressure bar tests on sandstone in coalmine under cyclic wetting and drying," Rock and Soil Mechanics, vol. 34, no. 9, pp. 2557-2562, 2013, in Chinese.

[29] Q. Y. Ma, P. Y. Yu, and P. Yuan, "Experimental study on creep properties of deep siltstone under cyclic wetting and drying," Chinese Journal of Rock Mechanics and Engineering, vol. 37, no. 3, pp. 593-600, 2018, (in Chinese). 